\title{
Steroid Induced Gastrointestinal Perforation in a Traumatic Injury. Atypical Complication to a Common Drug
}

\author{
MOHAMMAD ASHRAF, ${ }^{1}$ USMAN AHMAD KAMBOH ${ }^{2}$ \\ ${ }^{1}$ University of Glasgow School of medicine, Glasgow, UK \\ ${ }^{2}$ Department of Neurosurgery, Jinnah Hospital, Lahore
}

DOI: https://doi.org/10.36552/pjns.v23i3.367

\begin{abstract}
We report this case of a male patient with cervical spine injury following shallow water diving. With power of $3 / 5$ in all 4 limbs and grade 2 subluxation (C5/C6) the patient was operated on undergoing a 360 degree fixation and unlocking of facets; he was administered steroids and developed abdominal distention. An eventual CT scan showing a pneumoperitoneum revealed he had developed a gastrointestinal perforation. GI perforation is a less well recognized side effect of steroids. It can be difficult to diagnose, as the steroids can mask the symptoms of gut perforation by reducing the clinical expression of peritonitis, and a serious complication; been reported in the literature to have a mortality ranging from $27 \%$ to a $100 \% .{ }^{1-3}$ We report this case as a clinical reminder of the risk of GI perforation from steroid use and to emphasize the role of a multi-disciplinary team in the management of trauma patients.
\end{abstract}

Keywords: Neurosurgery, Trauma, Gastrointestinal Perforation, Steroids.

Abbreviations: GI: Gastroentestinal. MDT: Multidisciplinary Terms.

\section{INTRODUCTION}

Pakistan is predicted to have an incidence of traumatic spinal cord injury from anywhere between 25.5 to 130.7 cases/million/year. However there is no officially recorded figure due to a lack of registries for spinal injuries throughout the countries major trauma centres and a result of under reporting and improper record keeping ${ }^{4}$. Centres receive high volumes of traumatic spinal cord injuries due to factors unique to third world countries.

The role of steroids, such as dexamethasone, after traumatic spinal injury is still questionable; steroids are however regularly used before and after operating. Gut perforation is a less well recognized complication of steroid therapy, difficult to diagnose and serious. Patients on systemic steroid therapy are at increased risk of diffuse peritonitis, especially from gastrointestinal perforation ${ }^{5}$. This case cautions readers to be mindful of an uncommon side effect of a regularly used drugs, which can be life threatening.

\section{CASE REPORT}

\section{Case Presentation}

A 40-year-old male had arrived at the accident and emergency department on the $4^{\text {th }}$ of June 2018 at Jinnah hospital Lahore, Allama Iqbal Medical College, after a history of shallow water diving in a canal 6 hours prior and complained of weakness in all four limbs. A primary survey and resuscitation were carried out according to ALS guidelines. Power revealed in both the upper and lower limbs was grade 3/5 while the rest of the neurological and systemic examination was unremarkable. He was admitted into our neurosurgery ward and radiographs revealed fractures in his cervical spine.

\section{Investigations}

We X-rayed his cervical spine which showed a C5-C6 grade 2 subluxation (figure 1A). A 3-D CT reconstruction (figure 2) showed locked facets. Serum electrolyte values were taken on the $10^{\text {th }}$ post-operative 
day following complaints of abdominal distention. They showed moderate hypokalemia, $2.7 \mathrm{~m} . \mathrm{mol} / \mathrm{l}$. When the abdominal distention did not settle after potassium replacement, we CT scanned his abdomen revealing a pneumoperitoneum (figure 3). Troponin levels were 0.726 on the $21 \mathrm{st}$ post-operative day, (normal range $<0.034 \mathrm{ng} / \mathrm{ml}$ ).
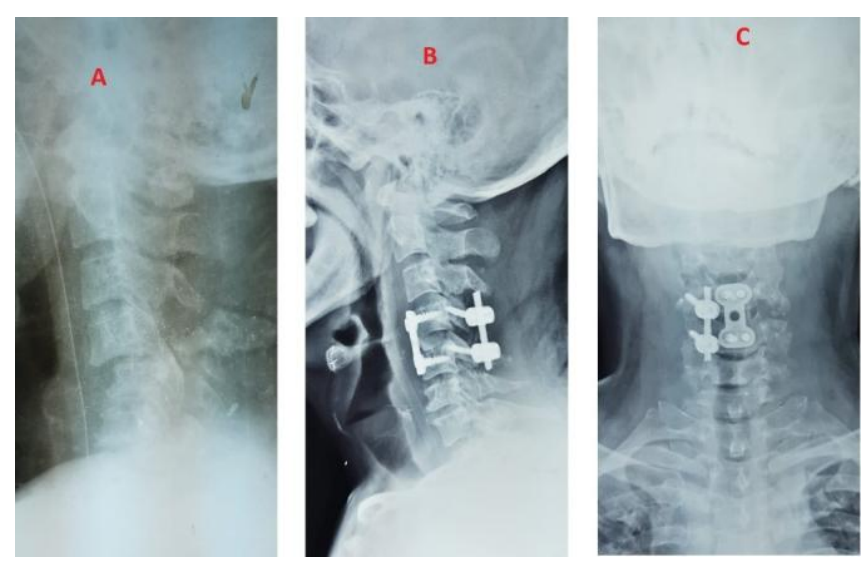

Fig. 1: Plain film X-Ray from left to right: A-Pre-operative lateral showing a grade 2 C5-C6 subluxation $B$ Post operative lateral C-Post operative posterior.
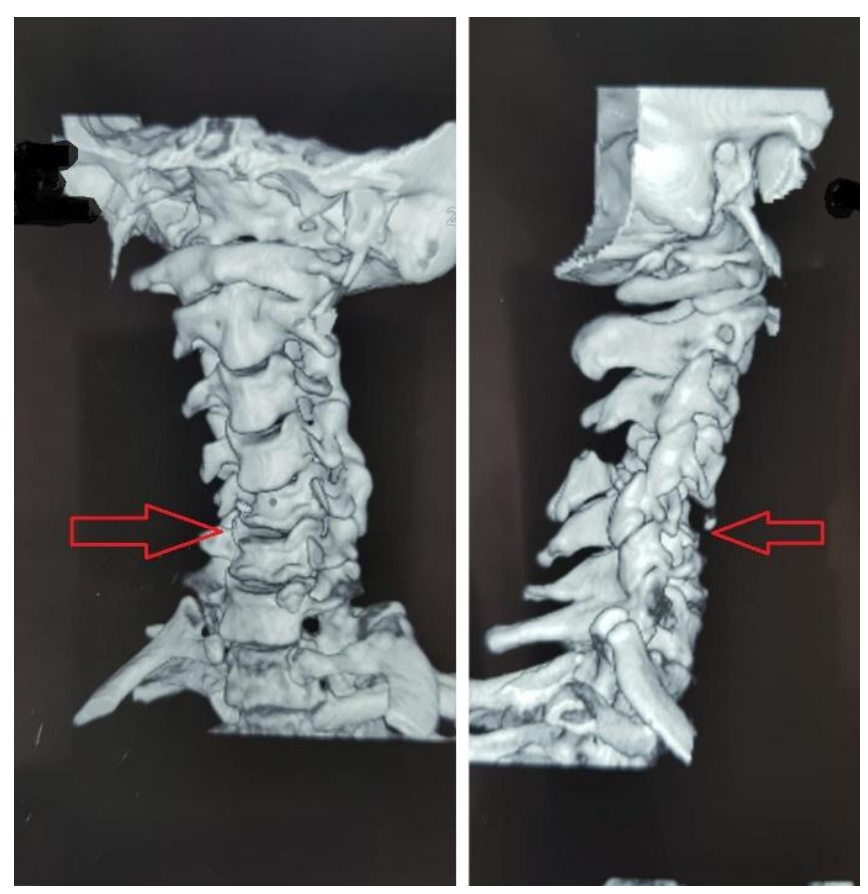

Fig. 2: $3 D$ Reconstruction of CT images demonstrating locked facets at C5/C6.

\section{Treatment}

Skull traction was applied on the day of admission and the patient was planned for an anterior and posterior fixation. He was operated on the sixth post admission day and underwent unlocking of facets posteriorly. Lateral mass fixation was carried out unilaterally as the lateral mass on the right side was fractured and shattered. The patient was then placed in a supine position and anterior cervical decompression and stabilization was done at C5-C6 (figure 1B\&C). He had recovered from the aesthesia satisfactorily and his post-operative neurological status improved to grade $4 / 5$ in all muscle groups. Dexamethasone was administered for 11 days starting from the day of admission at $12 \mathrm{mg}$ and tapered down till the sixth post-operative day. It was administered again for 4 days from the $9^{\text {th }}$ to the $13^{\text {th }}$ post-operative day as after the initial regime the patient developed symptoms of lethargy and lassitude resulting in decrease limb movements which we had assumed was due to spinal cord swelling. He developed abdominal distention on the $10^{\text {th }}$ post-operative day, which we had considered to be paralytic ileus. Labs revealed hypokalemia which was initially resistant to potassium replacement, recommended by the nephrology team; his distention did not settle. He suffered an acute myocardial infarction after two days and Aspirin was administered as advised by the cardiology department for 3 days. The sequence of events in the management of the patient was more in the favour of hypokalemicparalytic ileus and treatment with high dose steroids resulted in decreased clinical expression of peritonitis masking the possibility of gut perforation. We then CT scanned his abdomen, which revealed a pneumoperitoneum (figure 3 ) and believe this was a

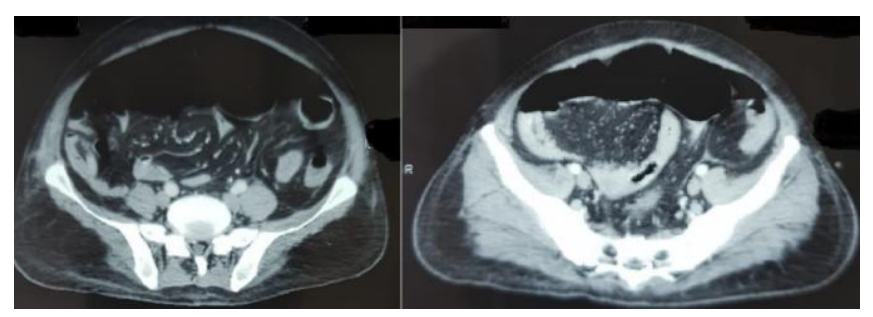

Fig. 3: Axial Section CT showing a pneumoperitoneum.

result of gut perforation secondary to steroid use. The patient underwent a mini-laparotomy through a lower midline incision by the general surgery team under local anaesthesia. The air was removed, confirmed by a post-operative X-Ray (figure 4) but no perforation was identified. We believed it was a sealed perforation. 


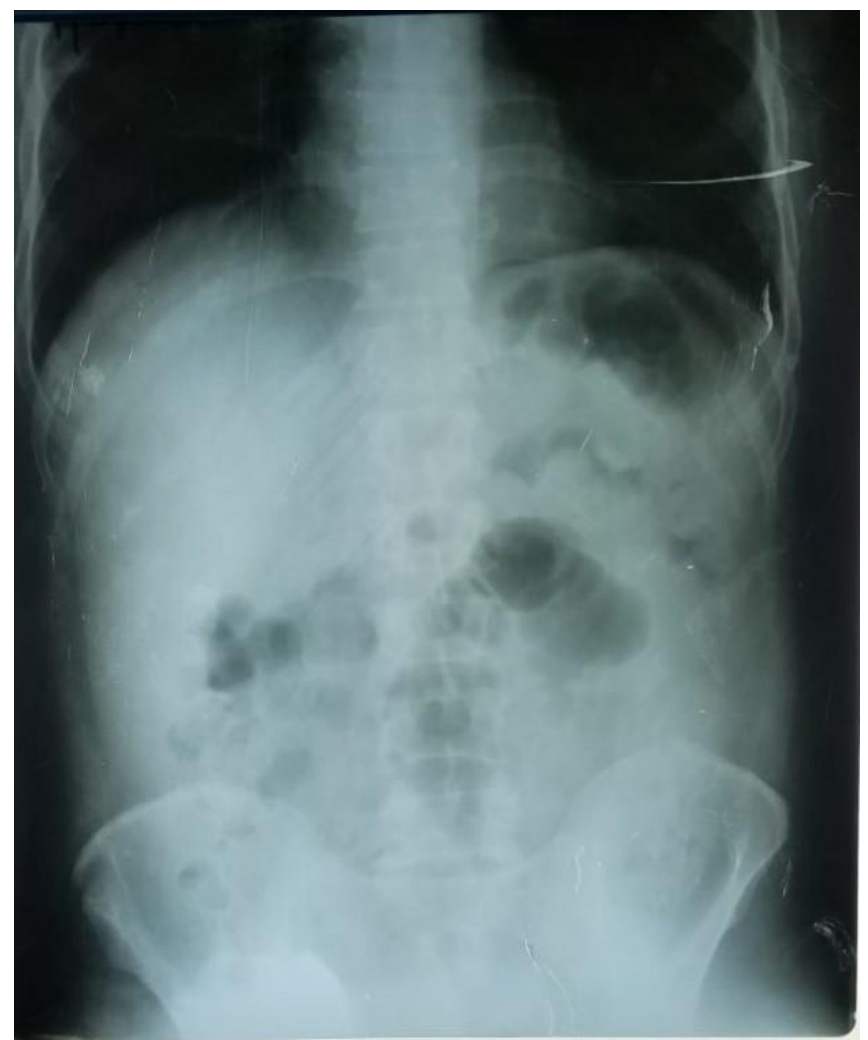

Fig. 4: Post operative X-Ray showing no signs of air.

\section{DISCUSSION}

Gastric perforation because of treatment with steroids is reported in literature ${ }^{6,7}$. Studies conducted highlight its importance as mortality because of these perforations ranges from $27 \%$ to $100 \% .^{1-3}$ A study conducted by Stephen G. et.al showed that patients treated with steroids ranging from a low dose perioperative to high doses (>20 mg/day) were at a risk of suffering from gut perforations. ${ }^{8}$ The studies mean time for the appearance of symptoms was 8.3 days, which was consistent with our patient (10 days). We could not find a case for steroid induced gastrointestinal perforation in a post-operative cervical injury fixation patient regardless the importance of this case is to reemphasize that treatment with steroids can mask the symptoms of gut perforation by reducing the clinical expression of peritonitis.

This case signifies how team work between colleagues from a range of specialties was essential in achieving safe and effective patient care. Coordination between neurosurgeons, general surgeons, anaesthetists, cardiologists and nephrologists was crucial to the eventual safe recovery of our patient. In many developing countries like Pakistan there are no policies within hospitals to implement multidisciplinary team work. Lack of MDTs in hospital practice can be attributed to lack of communication, professional rivalry, differences in status within the medical hierarchy and an under appreciation of the importance of what other colleagues can bring to the table. ${ }^{9}$ When being cared for by an MDT, the patient's confidence within their own team improves as they are being treated by a group of experts rather than just one clinician.

\section{CONCLUSION}

Clinicians should be observant for even mild abdominal distension when a patient has been on steroid therapy and make an early diagnosis given the possibility of gut perforation. MDTs reduce the likelihood of adverse hospital events, they also improve patient outcomes and patient satisfaction ${ }^{10}$ and thus we hope to encourage readers in the setting's similar to ours to incorporate a multi-disciplinary team approach in their own practice.

\section{ACKNOWLEDGEMENT}

We are thankful to the brother of our patient who gave signed consent as the patient found it difficult to write at the time. We would like to thank our nursing staff for physical retrieval of patient notes from the archives and our department chairman Professor Naveed Ashraf who approved the opportunity to write this case report.

\section{Additional Information}

Disclaimer: Presented as a poster at the Glasgow University Surgical Society's $10^{\text {th }}$ National Undergraduate Conference. Conferences proceedings/abstracts were not published.

Disclosures: Authors report no conflict of interest.

Human Subjects: Consent was obtained by patients and participants in this study.

\section{Conflicts of Interest:}

In compliance with the ICMJE uniform disclosure form, all authors declare the following:

Financial Relationships: All authors have declared that they have no financial relationships at present or within the previous three years with any organizations that might have an interest in the submitted work.

Other Relationships: All authors have declared that there are no other relationships or activities that could appear to have influenced the submitted work.

Funding Disclosure: No funding was received to write this case report, it was done for an educational perspective. 


\section{Address for Correspondence: \\ Mohammad Ashraf \\ ${ }^{1}$ University of Glasgow Wolfson School of Medicine, University Avenue, G12 8QQ, Glasgow, UK Email:mohammad_5676@hotmail.com}

\section{REFERENCES}

1. Canter JW, Shorb PE, Jr. Acute perforation of colonic diverticula associated with prolonged adrenocorticosteroid therapy. Am J Surg. 1971; 121: 46-50.

2. Sterioff S, Orringer MB, Cameron JL. Colon perforations associated with steroid therapy. Surgery 1974; 75: 56-58.

3. Warshaw AL, Welch JP, Ottinger LW. Acute perforation of the colon associated with chronic corticosteroid therapy. AM J Surg 1976; 131: 442-446.

4. Rahimi-Movaghar V, Sayyah M, K, Akbari H, Khorramirouz R, Rasouli M, R, Moradi-Lakeh M,
Shokraneh F, Vaccaro A, R: Epidemiology of Traumatic Spinal Cord Injury in Developing Countries: A Systematic Review. Neuroepidemiology 2013; 41: 65-85. Doi: 10.1159/000350710

5. negaux F, Chenard X, Wechsler B, Boutin Z, Chigot J, P: Diffuse Peritonitis in Steroid-Treated Patients. Dig Surg. 1998; 15: 247-251. Doi: 10.1159/000018622

6. Sautter RD, Ziffren SE. Adrenocortical steroid therapy resulting in unusual gastrointestinal complications. Arch Surg 1959; 79:346-351.

7. ReMine SG, McIlrath DC. Bowel perforation in steroid-treated patients. Annals of Surgery, 1980; 192 (4): 581-586.

8. Tzenalis A, Sotiriadou C. Health promotion as a multiprofessional and multi-disciplinary work. Int J Caring Sci. 2010; 3: 49-55.

9. Epstein NE. Multidisciplinary in-hospital teams improve patient outcomes: A review. SurgNeurol Int. 2014; 5 (Suppl 7): S295-303. Published 2014 Aug 28. doi:10.4103/2152-7806.139612.

\begin{tabular}{|c|c|c|c|}
\hline \multicolumn{4}{|c|}{ AUTHORSHIP AND CONTRIBUTION DECLARATION } \\
\hline Sr.\# & Author's Full Name & Intellectual/Contribution to Paper in Terms of: & \multirow[b]{2}{*}{$\begin{array}{l}\text { Signature by } \\
\text { the author(s) }\end{array}$} \\
\hline 1. & $\begin{array}{l}\text { Mohammad Ashraf } \\
\text { (Main/Principal Author). }\end{array}$ & 1. Paper writing, methodology and literature review. & \\
\hline 2. & $\begin{array}{l}\text { Usman Ahmad } \\
\text { (2nd Author) }\end{array}$ & $\begin{array}{l}\text { 2. Study design, Analysis of data and interpretation of } \\
\text { results etc. }\end{array}$ & wh \\
\hline
\end{tabular}

Date of Submission: 10-09-2019

Date of Revision: 20-09-2019

Date of Online Publishing: 25-09-2019

Date of Print: 30-09-2019 